\title{
Covalent Modification of Reduce Graphene oxide with Piperazine as a novel nanoadsorbent for removal of $\mathrm{H}_{2} \mathrm{~S}$ gas
}

Masoud Khaleghi Abbasabadia*, Saeed Khodabakhshii ${ }^{\mathrm{b}}$, Hamid Reza Esmaili Zand ${ }^{\mathrm{c}}$, Alimorad Rashidi $^{\mathrm{a}}$, Pooya Gholami ${ }^{\mathrm{a}}$, Zahra Sherafati ${ }^{\mathrm{a}}$

${ }^{a}$ Nanotechnology Research Center. Research Institute of Petroleum Industry (RIPI), Tehran, Iran. ${ }^{b}$ Energy Safety Research Institute, Swansea University, Bay Campus, Swansea SA1 8EN, U.K. 'Department of Chemistry, Iran University of Science and Technology, Tehran, Iran

*Corresponding author; Email: masoudkhalegiabbasabadi@gmail.com; Tel: $+98(991) 6886865$

\begin{abstract}
In the present research, piperazine grafted-reduced graphene oxide RGO-N-(piperazine) was synthesized through a three-step reaction and employed as a highly efficient nanoadsorbent for $\mathrm{H}_{2} \mathrm{~S}$ gas removal. Temperature optimization within the range of $30-90{ }^{\circ} \mathrm{C}$ was set which significantly improved the adsorption capacity of the nanoadsorbent. The operational conditions including the initial concentration of $\mathrm{H}_{2} \mathrm{~S}(60000 \mathrm{ppm})$ with $\mathrm{CH}_{4}(15 \mathrm{vol} \%), \mathrm{H}_{2} \mathrm{O}(10 \mathrm{vol} \%)$, $\mathrm{O}_{2}$ (3 vol\%), and the rest by helium gas and gas hour space velocity (GHSV) 4000-6000 $\mathrm{h}^{-1}$ were examined on adsorption capacity. The results of the removal of $\mathrm{H}_{2} \mathrm{~S}$ after $180 \mathrm{~min}$ by RGO-N-(piperazine), reduced graphene oxide (RGO), and graphene oxide (GO) were reported as 99.71, 99.18, and 99.38, respectively. Also, the output concentration of $\mathrm{H}_{2} \mathrm{~S}$ after 180 min by RGO-N-(piperazine), RGO, and GO were found to be 170, 488, and $369 \mathrm{ppm}$, respectively. Both chemisorption and physisorption are suggested as mechanism in which the chemisorption is based on an acid-base reaction between $\mathrm{H}_{2} \mathrm{~S}$ and amine, epoxy, hydroxyl functional groups on the surface of RGO-N(piperazine), GO, and RGO. The piperazine augmentation of removal percentage can be attributed to the presence of amine functional groups in the case of RGO-N-(piperazine) versus RGO and GO. Finally, analyses of the equilibrium models used to describe the experimental data showed that the three-parameter isotherm equations Toth and Sips provided slightly better fits compared to the three-parameter isotherms.
\end{abstract}

Keywords: Piperazine-reduced graphene oxide, $\mathrm{H}_{2} \mathrm{~S}$ removal, Chemisorption and Physisorption, Nanoadsorbent

\section{INTRODUCTION}

Gas emissions are recognized as one of the main sources causing global warming. These emissions, owing to their chronic exposure, can lead to several negative effects such as photochemical smog and green-house effect [1-6]. Carbon monoxide $(\mathrm{CO})$, hydrogen sulfide $\left(\mathrm{H}_{2} \mathrm{~S}\right)$, and sulfur oxides $\left(\mathrm{SO}_{\mathrm{x}}\right)$ are among these gasses that are harmful, even at low concentrations, for human health and environment [7-12]. Among above compounds, $\mathrm{H}_{2} \mathrm{~S}$ is highly toxic 
and correspondingly resulted in irreparable effects in global environment. There are many sources producing and releasing $\mathrm{H}_{2} \mathrm{~S}$ into the atmosphere. As an example, degradation of sulfur containing compounds and proteins can lead to $\mathrm{H}_{2} \mathrm{~S}$ emission. Treatment facilities of wastewater are also other sources emitting $\mathrm{H}_{2} \mathrm{~S}$. In addition, petroleum refining, natural gas processing, paper manufacturing, and livestock farming are among activities that lead to releasing $\mathrm{H}_{2} \mathrm{~S}$ [13]. Previously, the removal processes of $\mathrm{H}_{2} \mathrm{~S}$ (to eliminate it chemically) were expensive and had many limitations such as need to specific equipment and massive energy. In other words, the elimination of $\mathrm{H}_{2} \mathrm{~S}$ with costeffective methods has become a critical issue and attracted attentions of researchers around the world to develop novel materials. Carbon nanomaterials and metal oxide, due to their outstanding properties such as high stability, capability for chemical manipulations, high surface area, and cheapness are known as one of the most promising agents to address a wide range of current challenges in the different fields [14-17]. One of the most famous and practical twodimensional structures which has a $\mathrm{sp}^{2}$ carbonaceous network and exceptional properties is graphene [18-23]. Graphene could be prepared by simple steps from reduction of graphene oxide (GO). GO contains oxygen functionalities such as epoxide, ketone and carbonyl, and hydroxy groups [24, 25]. However, these functional groups might reduce its performance in some applications because of decrease in conductivity properties of GO. On the other hand, owing to the presence of these oxygen-containing functional groups, it gains a great option such as the ability of simple functionalization. Unique graphene and GO properties make them outstanding substrates for use in numerous fields [26-29]. As a result, both these carbonaceous nanomaterials, which one contains a high level of oxygen functionalities and another one has a thick conductive plane, are used widely in modern academic society. However, the majority of the oxygen groups of GO could be removed by various reductants to convert it into graphene, and subsequently, prepared graphene could be further functionalized. The most common reducing agents to remove oxygen groups of GO include hydrazine, sodium borohydride, hydroquinone, and 1,1-dimethylhydrazine [30, 31]. Reduction of GO with each of these reductants leads to a specific graphene with new properties. In addition to reductant effect, other factors can influence the properties of prepared graphene, including functional group, reaction temperature, oxidation methods, and used solvent.

In this research, to synthesize an efficient material for the removal of $\mathrm{H}_{2} \mathrm{~S}$, GO was first reduced by sodium borohydride to prepare graphene, and then, prepared graphene was functionalized by piperazine to achieve effective nanoadsorbent. The synthesized nanoadsorbent was characterized by X-ray diffraction (XRD), X-ray photoelectron spectroscopy (XPS), scanning electron microscopy (SEM), Fourier-transform infrared (FT-IR), and transmission electron microscopy (TEM). Both GO and piperazine-modified reduced GO were used for $\mathrm{H}_{2} \mathrm{~S}$ gas removal. According to the obtained results, piperazine-modified reduced GO, due to the presence of amine functional groups and providing additional polar sites, enhanced the adsorption of $\mathrm{H}_{2} \mathrm{~S}$. Consequently, synthesized nanoadsorbent might be considered as a high capacity adsorbent for removal of hazardous acid gases.

Herein, we would like to report the preparation of a new nano adsorbent base on Reduce Graphene oxide functionalized with Piperazine (RGO-N-(piperazine)) and employing it as a nano adsorbent for the first time. The aims of this research are: 1) to characterize the structural and chemical properties of the newly synthesized RGO-N(piperazine), and 2) to examine whether the functionalization on the basis of graphene oxide can act as a nano 
adsorbent. According to the gain results, RGO-N-(piperazine) nano adsorbent can be used as a $\mathrm{H}_{2} \mathrm{~S}$ gas adsorbent at high concentrations of $\mathrm{H}_{2} \mathrm{~S}$ gas with high efficiency. This study is reported for the first time in this research. The results revealed that RGO-N-(piperazine) has better $\mathrm{H}_{2} \mathrm{~S}$ adsorption performance due to the presence of amine functional groups on the surface of graphene sheets.

\section{EXPERIMENTAL}

\subsection{General}

Natural flake graphite (99.95\%), sodium borohydride (98.0\%), potassium permanganate (99\%), sulfuric acid (>98\%), piperazine, EtOH and $\mathrm{H}_{2} \mathrm{O}_{2}(30 \%)$ were purchased from Merck. The apparatuses utilized in this research were power X-ray diffractometer, Philips PW-1840 equipped with $\mathrm{Cu}$ Ka radiation source, and a scanning electron microscope (SEM) (TESCAN). FT-IR spectroscopy was obtained using Broker (VERTEX 70) spectrum, while X-ray diffraction technique and scanning electron microscopy were used to characterize the samples. To characterize functional groups of graphene sheets after treatment, X-ray photoelectron spectra (XPS) were obtained using a VG Escalab 200R spectrometer equipped with a hemispherical electron analyzer.

\subsection{Preparation of $G O$}

The graphene oxide sheets were prepared according to the modified Hummer's method [32]. For pre-oxidation of graphite solid powder, $125 \mathrm{ml}$ of concentrated sulfuric acid was added to $2.5 \mathrm{~g}$ of the initial graphite powder and the mixture stirred at room temperature for 24 hours. After the time has elapsed, $15 \mathrm{~g}$ of oxidizing agent $\left(\mathrm{KMnO}_{4}\right)$ was gradually added to the reaction mixture. After that, the reaction was stirred for another 72 hours at $55^{\circ} \mathrm{C}$. Then, a mixture of $25 \mathrm{ml}$ of $\mathrm{H}_{2} \mathrm{O}_{2} 30 \%$ and $200 \mathrm{ml}$ of water was added to the reaction mixture. The resulting mixture was centrifuged and rinsed several times with a mixture of deionized water and $\mathrm{HCl} 10 \%$ to remove impurities from the product. Finally, brown solid of GO was obtained after drying in an oven at $65^{\circ} \mathrm{C}$.

\subsection{Synthesis Preparation of graphene oxide grafted with piperazine}

$2.5 \mathrm{~g}$ of GO was dispersed in $125 \mathrm{~mL}$ of water, followed by the addition of $7.5 \mathrm{~g}$ of piperazine in $125 \mathrm{~mL}$ of ethanol. The mixture was allowed to stir for $24 \mathrm{~h}$ under reflux before the separation of the resulting GO-NH (filtration, washing with water and ethanol, and drying at $80^{\circ} \mathrm{C}$ ). Modification of GO with piperazine was carried out by ring opening of epoxide group and formation of C-N band on GO surface [33].

\subsection{Preparation of piperazine grafted-reduced graphene oxide RGO-N-(piperazine)}


As-prepared GO supported piperazine was diluted in $540 \mathrm{~mL}$ DI water and $3 \mathrm{mg} / \mathrm{mL} \mathrm{NaBH} 4(7.50 \mathrm{~g})$ was added to it. The mixture was stirred at $80^{\circ} \mathrm{C}$ for $1 \mathrm{~h}$ under reflux. Finally, the collected black product was dried under oven vacuum at $45{ }^{\circ} \mathrm{C}[25]$.

\section{5. $\quad \mathrm{H}_{2} \mathrm{~S}$ adsorption set-up}

The schematic of the laboratory absorption of hydrogen sulfide gas is shown in Fig.1. The amount of $\mathrm{H}_{2} \mathrm{~S}$ gas input required for testing in this study was $60000 \mathrm{ppm}$, along with $\mathrm{CH}_{4}(15 \mathrm{vol} \%), \mathrm{H}_{2} \mathrm{O}(10 \mathrm{vol} \%), \mathrm{O}_{2}$ (3 vol\%), and the rest by helium gas. The concentration of feed and outlet hydrogen sulfide gas in this experiment was measured by a potentiometer titration instrument (Mettler DL 40GP) that equipped with an $\mathrm{Ag}-\mathrm{Ag}_{2} \mathrm{~S}$ electrode (DM 141-SC). A fixed base reactor with a diameter of $31 \mathrm{~mm}$ and a length of $500 \mathrm{~mm}$ was selected and $3 \mathrm{~g}$ of the desired adsorbent was placed inside the gas absorption reactor. The feed flow rate of gases mixture was $200 \mathrm{~mL} / \mathrm{min}$ absorption system and the amount of adsorbent weight was selected by the desired space velocity. The desired temperature was adjusted using a temperature controller.

\section{$<$ Fig. $1>$}

\section{Result and discussion}

\subsection{Characterization of the $G O$ and $R G O-N$-(piperazine) nanoadsorbents}

A schematic illustration of the three-step synthesis pf RGO-N-(piperazine) is shown in Scheme 1. In the first step, GO was initially prepared via oxidation of graphite powder with $\mathrm{KMnO}_{4}$ and $\mathrm{H}_{2} \mathrm{O}_{2}(30 \%)$ in acidic solution according to the Hummer's method. Afterward, GO was aminated through nucleophilic ring-opening of the epoxy groups on its surface upon treatment with piperidine. Finally, $\mathrm{GO}$ was reduced by $\mathrm{NaBH}_{4}$ in a manner of a previously reported method [29].

\section{< Scheme 1>}

The Fig. 2 shows a FT-IR spectrum for GO and RGO-N-(piperazine). Expectedly, the apparent difference between absorption bands suggests successful formation of RGO-N-(piperazine). The characteristic peak for hydroxyl group related to $\mathrm{C}-\mathrm{OOH}$ and $\mathrm{C}-\mathrm{OH}$ appeared in the range of $2550-3600 \mathrm{~cm}^{-1}$ as a broad peak. However, the concentration of $\mathrm{COOH}$ after reducing the $\mathrm{GO}$ decreased and was confirmed by the appearance of a less broad signal in the range of $300-3500 \mathrm{~cm}^{-1}$ for RGO-N-(piperazine) spectrum. Furthermore, the peaks at 1729, 1622, 1389 and $1070 \mathrm{~cm}^{-1}$ in GO spectrum can be assigned as the stretching vibrations of $\mathrm{C}=\mathrm{O}, \mathrm{C}=\mathrm{C}, \mathrm{C}-\mathrm{O}-\mathrm{C}$, and $\mathrm{C}-\mathrm{O}$, respectively [34]. The peak at $1232 \mathrm{~cm}^{-1}$ in Fig. $2 \mathrm{~b}$ can be attributed to the stretching vibration of the amino $\mathrm{C}-\mathrm{N}$ bond formed by amination of the 
GO with piperazine. Moreover, the characteristic stretching vibrations appearing at $3410 \mathrm{~cm}^{-1}$ in the spectrum of the RGO-N-(piperazine) (Fig. 2b) corresponds to the $\mathrm{N}-\mathrm{H}$ bond which was overlapped with the $\mathrm{O}-\mathrm{H}$ stretching vibration. In addition, the presence of the piperazine ring on the surface of $\mathrm{GO}$ is also ratified by appearance of the $\mathrm{C}-\mathrm{H}$ stretching vibration at $2908 \mathrm{~cm}^{-1}$ in the spectra of the RGO-N-(piperazine). This result clearly confirms the successful functionalization of the GO with piperazine functional groups [34].

\section{< Fig. $2>$}

The XRD patterns of GO and RGO-N-(piperazine) are depicted in Fig. 3. In the GO patterns, the distinctive peak (002) at near $2 \theta=12^{\circ}$ is related to the oxygen functional groups which are intercalated between graphene sheets during oxidation process. The diffraction peak at $2 \theta=49^{\circ}$ is related to (100) which can be observed at both GO and RGO$\mathrm{N}$-(piperazine). After modification of graphene oxide with piperazine, the intensity of the peak at $12^{\circ}$ was tangibly decreased in comparison with that of GO. In addition, the broad peak at about $2 \theta=24^{\circ}$ can be assigned as partially reduction of GO sheets. However, the peak at $2 \theta=12^{\circ}$ indicates the presence of oxygen functional groups even after functionalization of GO with piperazine [35].

\section{< Fig. $3>$}

X-ray photoelectron spectroscopy (Fig. 4(a)) was employed to examine the chemically structure of GO and RGO-N(piperazine). According to the XPS spectrum of RGO-N-(piperazine), the intensity of O $1 \mathrm{~s}$ decreased compared to that of GO, indicating the functionalization of GO with piperazine. Furthermore, the appearance of the $\mathrm{N} 1 \mathrm{~s}$ peak confirms the creation of nitrogen containing functional groups on the GO sheets [36]. The high resolution of XPS spectra of $\mathrm{C} 1 \mathrm{~s}, \mathrm{O} 1 \mathrm{~s}$ and $\mathrm{N} 1 \mathrm{~s}$ were investigated to further evaluate the quantity of the surface of GO and RGO-N(piperazine).

\section{< Fig. 4 >}

The Figure 4(b) illustrates the $\mathrm{C}$ 1s spectra of GO. The distinctive peaks at 285.1, 286.9, and $288.1 \mathrm{eV}$ are assigned as $\mathrm{sp}^{2} \mathrm{C}-\mathrm{C}$ bonds, $\mathrm{C}-\mathrm{O}$, and $\mathrm{C}=\mathrm{O}$, respectively. Fig. 4(c) shows the $\mathrm{O} 1$ s spectra of $\mathrm{GO}$ in which the peaks at 531.1 and $533.7 \mathrm{eV}$ are related to $\mathrm{C}-\mathrm{O}$ and $\mathrm{C}=\mathrm{O}$, respectively [37]. The high-resolution spectra of $\mathrm{C} 1 \mathrm{~s}$ for RGO-N(piperazine) is depicted in Fig. 4(d). Three distinctive peaks at about 285, 286.4, and $288.1 \mathrm{eV}$ are associated with C$\mathrm{C}, \mathrm{C}-\mathrm{N}$, and $\mathrm{C}=\mathrm{O}$, respectively. Therefore, the alteration of $\mathrm{C} 1 \mathrm{~s}$ for RGO-N-(piperazine) versus $\mathrm{GO}$ indicates the functionalization of $\mathrm{GO}$ with piperazine due to the creation of $\mathrm{C}-\mathrm{N}$ bonds. The formation of $\mathrm{C}-\mathrm{N}$ bonds was further confirmed by FTIR analysis. The N 1s spectra of RGO-N-(piperazine) is shown in Fig. 4(e). Two components in this spectrum at 399.1 and $401.6 \mathrm{eV}$ are attributed to the C-N and N-H bonds, respectively. The O 1s spectra of RGO-N- 
(piperazine) (Fig. 4(f)) reveals the presence of $\mathrm{C}=\mathrm{O}$ and $\mathrm{C}-\mathrm{O}$ bonds due to the two components at 531.2 and $532.9 \mathrm{eV}$, respectively, [38].

FE-SEM images in Fig. 5 (a-b) show that both GO and RGO-N-(piperazine) consist of randomly accumulated and wrinkled thin sheets closely associated with each other forming a disordered solid. The TEM image in Fig. 5 (c) shows the morphology of the as-prepared RGO-N-(piperazine) with crumpled layers. SEM and TEM images of GO and RGO-N-(piperazine) revealed that the functionalization procedure does not have any prominent impact on the morphology of graphene sheets.

\section{< Fig. 5 >}

Fig. 6 presents the energy dispersive X-ray (EDX) spectra of the RGO-N-(piperazine). As illustrated by these EDX images, the expected elemental components are per-formed for piperazine grafted-reduced graphene oxide RGO-N(piperazine) $(\mathrm{C}, \mathrm{O}, \mathrm{N})$. The mass percentages of the corresponding elements calculated from the EDX analysis are presented in Fig. 11. These results provided further evidence for successful grafting of GO films with piperazine ring and pre reduction with $\mathrm{NaBH}_{4}$.

\section{< Fig. 6 >}

\section{2. $\mathrm{H}_{2} \mathrm{~S}$ adsorption test}

Table 1 indicates the output concentration and percentage of $\mathrm{H}_{2} \mathrm{~S}$ removal by utilizing different nano adsorbents including RGO-N-(piperazine), GO, and RGO. As can be seen, the $\mathrm{H}_{2} \mathrm{~S}$ output concentration after 180 min for RGO$\mathrm{N}$-(piperazine), GO, and RGO were found as 90, 369, and $488 \mathrm{ppm}$, respectively. The removal percentage of $\mathrm{H}_{2} \mathrm{~S}$ after 180 min for RGO-N-(piperazine), GO, RGO were calculated as 99.84, 99.38, and 99.18, respectively. By using the $\mathrm{H}_{2} \mathrm{~S}$ gas feed concentration with a real sample in gas reservoir of Gachsaran area (Iran), the amount of $60000 \mathrm{ppm}$ was selected and to compare the performance of the nano adsorbents, certain amount of each adsorbent ( $3 \mathrm{~g}$ ) was separately used for the $\mathrm{H}_{2} \mathrm{~S}$ adsorption analysis.

\section{<Table 1>}

According to our achievements, all the adsorbents shows an appropriate capacity for the adsorption of $\mathrm{H}_{2} \mathrm{~S}$ gas. However, RGO-N-(piperazine) exhibits the best performance in comparison with GO and RGO. This can be related to the attached piperazine ring on the surface of GO and the presence of amine groups which enhance the physisorption and chemisorption of $\mathrm{H}_{2} \mathrm{~S}$ molecules. The improvement of adsorption capacity for $\mathrm{GO}$ in comparison with RGO can be related to the presence of oxygen containing functional groups such as hydroxyl, epoxy and carboxyl on the surface 
of GO. Hence, it can be concluded that the oxygen atoms on the GO sheets play an important role for the adsorption of $\mathrm{H}_{2} \mathrm{~S}$ molecules and this effect overcome the impact of the intensification of spacing layers which occurs by reduction of GO [39].

GO is converted to RGO by chemical and thermal methods. The spacing between the layers in GO is $8.27 \AA$ and also amount of oxygen in $\mathrm{GO}$ is $33.25 \%$. In the chemical method reduction by $\mathrm{NaBH}_{4}$, the interlayer distance between GO sheets increases to 9 and oxygen content decreases to below 20\% [39]. Comparison between the synthesized nano adsorbents shows that RGO-N-(piperazine) has the highest adsorption capacity for $\mathrm{H}_{2} \mathrm{~S}$ removal or lowest output, according to Table 1 . This observation can be attributed to the presence of additional piperazine rings on the surface of GO which can create amine functional groups. Piperazine is a six-member ring of organic base compounds. Therefore, it can be assumed that NH-containing rings undergoes an acid-base chemical reactions with $\mathrm{H}_{2} \mathrm{~S}$ gaseous molecules. Tables 2 indicates the textural properties of utilizing different nano adsorbents (GO, RGO and RGO-N(piperazine). The textural and surface properties of GO, RGO and RGO-N-(piperazine) are summarized in Table 2. According to results, the RGO-N-(piperazine) shows a larger pore volume, specific surface area, and pore size than GO and RGO.

\section{<Table 2>}

According to the Scheme 1, nano adsorbents have verity polar sites and chemical center. Therefore, $\mathrm{H}_{2} \mathrm{~S}$ adsorption capacity can be alternatively changed by various atoms and functional groups. The presence of piperazine functional group attached GO sheets provides polar sites and improves the chemical and physical adsorption. Piperazine is an organic base compound and functionalization of graphene oxide with piperazine leads to increase basicity properties, chemical reactivity and polarity sites of the RGO-N-(piperazine) through enhancing chemical reactivity by acid-base reactions. As a result, the adsorption capacity of RGO-N-(piperazine) is usually increased for the polar adsorbents via the formation of hydrogen bonds in the presence of piperazine ring [40-41].

Figure 7 shows the adsorption capacity of $\mathrm{H}_{2} \mathrm{~S}$ output concentration for the nano adsorbents including RGO-N(piperazine), RGO and GO. The $\mathrm{H}_{2} \mathrm{~S}$ output concentration after 60 minutes for RGO-N-(piperazine), RGO, and GO were found to be 104, 450, and 360 ppm, respectively. After that, there is no change between 60-120 minutes. Finally, the $\mathrm{H}_{2} \mathrm{~S}$ output concentration for RGO-N-(piperazine), RGO, and GO were found to be 135, 480, and $365 \mathrm{ppm}$, respectively. In addition, Fig. 7 demonstrates that the $\mathrm{H}_{2} \mathrm{~S}$ gas adsorption on the nano adsorbents decreases by increasing the contact time due to the saturation of surface functional groups with $\mathrm{H}_{2} \mathrm{~S}$ molecules.

\section{$<$ Fig. $7>$}


Figure 8 indicates the effect of temperature and GHSV on the $\mathrm{H}_{2} \mathrm{~S}$ adsorption. Owing to the fact that lower amount of GHSV reduces the $\mathrm{H}_{2} \mathrm{~S}$ concentration and enhances the capacity of the adsorbents, increasing the amount of GHSV from 4000 to $6000 \mathrm{~h}^{-1}$ leads to obvious augmentation of $\mathrm{H}_{2} \mathrm{~S}$ concentration. Since a lower GHVP will cause corrosion, high amount of GHPV was used. For industrial protection, the prepared nano materials can be used as an attachment to enhance the sweetening capacity of the unit.

\section{$<$ Fig. $8>$}

Fig. 9 indicates the effect of temperature on the $\mathrm{H}_{2} \mathrm{~S}$ adsorption. As shown in Fig. 9, the concentration of $\mathrm{H}_{2} \mathrm{~S}$ gas is decreased by increasing the temperature from $0{ }^{\circ} \mathrm{C}$ to higher temperatures leading to shorter residence time. In the range of $50-90{ }^{\circ} \mathrm{C}$, there is no any significant alteration for final concentration. This feature provides an opportunity for reducing the operational temperatures which is suitable for industrial applications.

\section{< Fig. 9>}

As summarized in Table 3, the experimental data resulted from the present work are compared with some previous reports. These results indicate that RGO-N-(piperazine) has higher $\mathrm{H}_{2} \mathrm{~S}$-adsorption capacity at $90^{\circ} \mathrm{C}$ (the highest temperature examined in this study). However, because of the differences in experimental conditions, comparison between these studies must be done with caution.

\section{<Table 3>}

\subsection{Adsorption Isotherms}

Adsorption equilibrium isotherm data for $\mathrm{H}_{2} \mathrm{~S}$ gas adsorption on GO, RGO and RGO-N-(piperazine) were obtained at pressures up to 1 bar using Langmuir [47], Toth [48] Freundlich [49], Sips [50] and Unilan [51]. The equation, the regression coefficient $\left(\mathrm{R}_{2}\right)$, and effective parameters for each isotherm are given in Table 4 . By non-linear regression models, the experimental data were fitted by different isotherms using CF tools. According to the Table 4, the $\mathrm{R}_{2}$ values of all the isotherms studied are close to unity, indicating that all of them are good models for the adsorption of $\mathrm{H}_{2} \mathrm{~S}$ gas by GO, RGO and RGO-N-(piperazine). Also, the Langmuir equation appeared to provide a better fit for the initial $\mathrm{H}_{2} \mathrm{~S}$ gas adsorption by RGO-N-(piperazine), while slightly higher $\mathrm{R}_{2}$ values were observed for Sips and Toth isotherms. For the sake of clarity, only the Langmuir and Toth isotherms are presented in Fig. 10. 


\section{<Table 4>}

$<$ Fig. 10>

\section{CONCLUSIONS}

In this study, GO, RGO, and RGO-N-(piperazine) were applied as adsorbents for the elimination of $\mathrm{H}_{2} \mathrm{~S}$ gas. GO was synthesized by modified Hummer's method and functionalized through a one-step chemical reaction with piperazine. The results revealed that RGO-N-(piperazine) has better $\mathrm{H}_{2} \mathrm{~S}$ adsorption performance due to the presence of amine functional groups on the surface of graphene sheets. The presence of nitrogen atoms in the piperazine rings can provide additional polar sites on the surface of graphene sheets to enhance the interaction between $\mathrm{H}_{2} \mathrm{~S}$ molecules and amine functional groups during physisorption and chemisorption process. Furthermore, the attendance of basal sites at amine functional groups accelerate the acid-base reaction between amine functional groups and $\mathrm{H}_{2} \mathrm{~S}$ molecules. In general, functionalization of GO with nitrogen containing functional groups can be utilized as a high capacity adsorbent for removal of hazardous acid gases.

\section{ACKNOWLEDGEMENT}

The authors wish to thank the Research Institute of Petroleum Industry (RIPI), is also greatly acknowledged for technical support.

\section{References}

1. H. Rodhe, Science. 248, 1217 (1990)

2. D.A. Lashof, D.R. Ahuja, Nature. 344, 529 (1990)

3. R. Dickerson, S. Kondragunta, G. Stenchikov, K. Civerolo, B. Doddridge, B. Holben, Science. 278, 827 (1997)

4. J. Q. Koenig, W.E. Pierson, R. Frank, Environmental research. 22, 145 (1980)

5. G. D'amato, G. Liccardi, M. D'Amato, Journal of investi-gational allergology \& clinical immunology. 10, 123 (2000)

6. N. Stjernberg, A. Eklund, L. Nyström, L. Rosenhall, A. Emmelin, L. Strömqvist, European journal of respiratory dis-eases. 67, 41 (1985)

7. C.R. Usher, A.E. Michel, V.H. Grassian, Chemical reviews. 103, 4883 (2003) 
8. C.K. Chan, X. Yao, Atmospheric environment. 42, 1 (2008)

9. J. Wang, C. Yang, Y.R. Zhao, H.L. Fan, Z.D. Wang, J. Shangguan, J. Mi, Industrial \& Engineering Chemistry Research. 56, 12621 (2017)

10. M. Khabazipour, M. Anbia, Industrial \& Engineering Chemistry Research. 58, 22133 (2019)

11. K. Ciahotný, V. Kyselová, Energy \& Fuels. 33, 5316 (2019)

12. W. Quan, X. Wang, C. Song, Energy \& Fuels. 31, 9517 (2017)

13. M. Syed, G. Soreanu, P. Falletta, M. Béland, Canadian Biosystems Engineering. 48, 2 (2006).

14. E. Llobet, J. Brunet, A. Pauly, A. Ndiaye, C. Varenne, Sensors. 17, 391(2017)

15. S. Khodabakhshi, P.F. Fulvio, E. Andreoli, Carbon. 604, 162 (2020). (b) S. Dastkhoon, Z. Tavakoli, S. Khodabakhshi, M. Baghernejad and M.K. Abbasabadi, New J. Chem. 39, 7268 (2015). (c) S. Khodabakhshi, M. Khalegi Abbasabadi, S. Heydarian, S. Gharehzadeh Shirazi and F. Marahel, Letters in Organic Chemistry. 12, 465 (2015). (d) S Khodabakhshi, MK Abbasabadi, M Baghrnejad, F Marahel, Journal of the Chinese Chemical Society. 62, 9 (2015), (e) A. Trégouëta, M. Khaleghi Abbasabadib, P. Gholami, Anal. Method Environ. Chem. J. 3, 5 (2020)

16. (a) A.M. Rashidi, M. Mirzaeian, S. Khodabakhshi, Journal of natural gas science and engineering. 25, 103 (2015) (b) P. Gholami, A.M. Rashidi, M. Khaleghi Abbasabadi, M. Pourkhalil, M. Jahangiri, N. Izadi, Research on Chemical Intermediates. (2020) https://doi.org/10.1007/s11164-020-04181-0. (c) M. Khaleghi Abbasabadi, D. Azarifar, Applied Organometallic Chemistry. (2020) https://doi.org/10.1002/aoc.5872. (d) A. Rashidi, Z. Tavakoli, Y. Tarak, S. Khodabakhshi, M. Khaleghi Abbasabadi, Journal of the Chinese Chemical Society. 63, 399 (2016)

17. T.P. Fellinger, F.D.R. Hasché, P. Strasser, M. Antonietti, Journal of the American Chemical Society. 134, 4072 (2012)

18. A.K. Geim, K.S. Novoselov, Nanoscience and technology, https://doi.org/10.1142/9789814287005-0002

19. H.R. Esmaili Zand, H. Ghafuri, A. Rashidizadeh, Z. Khoushab, Industrial \& Engineering Chemistry Research. 58, 5379 (2019)

20. H.R.E. Zand, H. Ghafuri, N. Ghanbari, ChemistrySelect, 3, 8229 (2018)

21. C. Berger, Z. Song, X. Li, X. Wu, N. Brown, C. Naud, D. Mayou, T. Li, J. Hass, A.N. Marchenkov, Science. 312, 1191 (2006)

22. C.E.N.E.R. Rao, A.E.K. Sood, K.E.S. Subrahmanyam, A. Govindaraj, Angewandte Chemie International Edition. 48,7752 (2009)

23. C. Rao, A. Sood, R. Voggu, K. Subrahmanyam, The Journal of Physical Chemistry Letters. 1, 572 (2010) 
24. W. Cai, R.D. Piner, F.J. Stadermann, S. Park, M.A. Shaibat, Y. Ishii, D. Yang, A. Velamakanni, S.J. An, M. Stoller, Science. 321, 1815 (2008)

25. A. Lerf, H. He, M. Forster, J. Klinowski, The Journal of Physical Chemistry B.102, 4477 (1998)

26. S. Khodabakhshi, F. Marahel, A. Rashidi, M.K. Abbasabadi, Journal of the Chinese Chemical Society. 62, 389 (2015)

27. M. Khaleghi-Abbasabadi, D. Azarifar, Research on Chemical Intermediates. 45, 2095 (2019)

28. D. Azarifar, M. Khaleghi-Abbasabadi, Research on Chemical Intermediates. 45, 199 (2019)

29. M.K. Abbasabadi, A. Rashidi, S. Khodabakhshi. Journal of Natural Gas Science and Engineering. 28, 87 (2016)

30. S. Stankovich, D.A. Dikin, R.D. Piner, K.A. Kohlhaas, A. Kleinhammes, Y. Jia, Y. Wu, S.T. Nguyen, R.S. Ruoff, carbon. 45, 1558 (2007)

31. S. Stankovich, D.A. Dikin, G.H. Dommett, K.M. Kohlhaas, E.J. Zimney, E.A. Stach, R.D. Piner, S.T. Nguyen, R.S. Ruoff, Nature, 442, 282 (2006)

32. W.S. Hummers Jr, R.E. Offeman, Journal of the american chemical society. 80, 1339 (1958)

33. E. Rodrigo, B.G. Alcubill, R. Sainz, J.G. Fierro, R. Ferritto, M.B. Cid, Chemical Communications. 50, 6270 (2014)

34. M. Khaleghi Abbasabadi, A. Rashidi, J. Safaei-Ghomi, S. Khodabakhshi, R. Rahighi, Journal of Sulfur Chemistry. $36,660(2015)$

35. H. Kim, K.Y. Park, J. Hong, K. Kang, Scientific reports. 4, 5278 (2014)

36. W. He, C. Jiang, J. Wang, L. Lu, Angewandte Chemie International Edition. 53, 9503 (2014)

37. L. Qu, Y. Liu, J.B. Baek, L. Dai, ACS nano. 4, 1321 (2010)

38. S. Pei, H.M. Cheng, Carbon. 50. 3210 (2012)

39. Y. Geng, S.J. Wang, J.K. Kim, science. 336, 592 (2009)

40. A. Mohamadalizadeh, J. Towfighi, A. Rashidi, A. Mohajeri, M. Golkar, Industrial \& engineering chemistry research. 50, 8050 (2011)

41. R. C. Bansal, M.Goyal, Activated carbon a. CRC press: 2005.

42. T.J. Bandosz, Journal of colloid and Interface Science. 246, 1 (2002)

43. J.P. Boudou, M. Chehimi, E. Broniek, T. Siemie-niewska, J. Bimer, Carbon. 41, 1999 (2003)

44. O. Mabayoje, M. Seredych, T.J. Bandosz, ACS applied materials \& interfaces. 4, 3316 (2012)

45. J.H. Tsai, F.T. Jeng, H.L. Chiang, Adsorption. 7, 357 (2001) 
46. Q. Chen, J. Wang, X. Liu, X. Zhao, W. Qiao, D. Long, L. Ling, Carbon. 49, 3773 (2011)

47. O. Mabayoje, M. Seredych, T.J. Bandosz, ACS Appl. Mater. Interfaces 4. 3316 (2012)

48. Y. Chuncai, Sep. Purif. Technol. 19, 237 (2000)

49. J.P.B. Chehimi, M.E. Broniek, T. Siemieniewska, J. Bimer, 2003. Carbon. 41, 1999 (2003)

50. H.M.F. Freundlich, J. Phys. Chem. 57, 1100 (1906)

51. I. Langmuir, Phys. Rev. 8, 149 (1916)

Table 1. $\mathrm{H}_{2} \mathrm{~S}$ removal percent and output concentration (ppm) of the as-prepared adsorbents (GHSV=4000 h-1 and $\mathrm{H}_{2} \mathrm{~S}$ feed concentration $\left.60000 \mathrm{ppm}\right)$.
Time (min)
Time (min)

Adsorbent

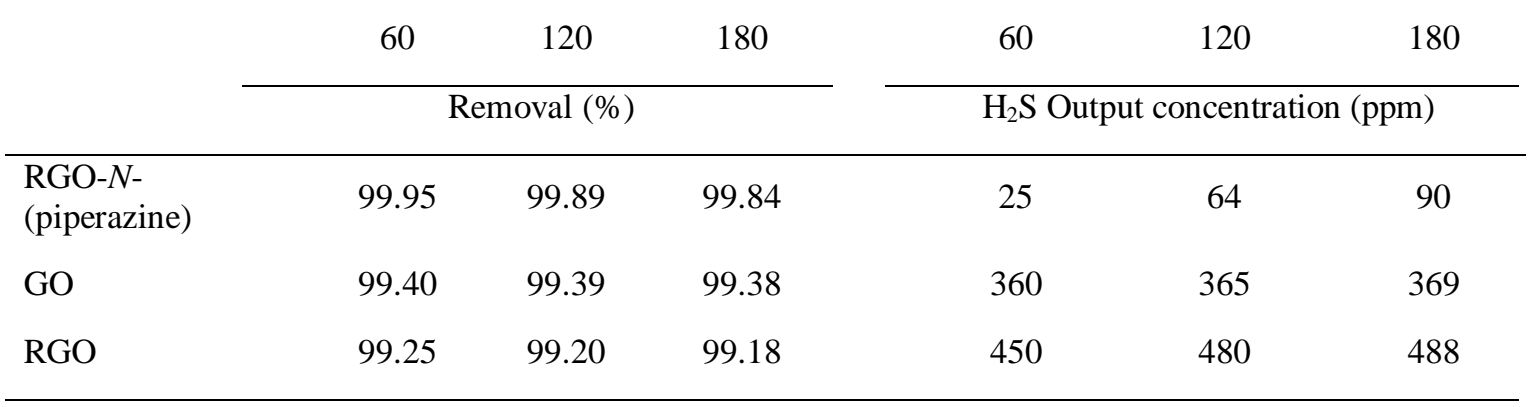

Table 2. Textural properties of GO, RGO and RGO-N-(piperazine).

\begin{tabular}{|c|c|c|c|}
\hline Sample & $\begin{array}{c}\text { Pore volume } \\
\left(\mathbf{c m}^{\mathbf{3}} \cdot \mathbf{g}^{-\mathbf{1}}\right)\end{array}$ & $\begin{array}{c}\text { Specific surface } \\
\text { area }\left(\mathbf{m}^{\mathbf{2}} \cdot \mathbf{g}^{\mathbf{- 1}}\right)\end{array}$ & Pore size (nm) \\
\hline GO & 0.138 & 104.449 & 5.3 \\
\hline RGO & 0.148 & 118.24 & 7.4 \\
\hline $\begin{array}{c}\text { RGO- } N- \\
(\text { piperazine })\end{array}$ & 0.214 & 170.65 & \\
\hline
\end{tabular}


Table 3. Comparison of $\mathrm{H}_{2} \mathrm{~S}$-adsorption capacity from the present work with those reported for other materials used in laboratory-scale $\mathrm{H}_{2} \mathrm{~S}$-adsorption processes.

\begin{tabular}{|c|c|c|c|c|c|}
\hline Entry & Adsorbent & $\begin{array}{c}\text { Temperature } \\
\left({ }^{\circ} \mathbf{C}\right)\end{array}$ & $\begin{array}{c}\text { Feed } \mathrm{H}_{2} \mathrm{~S} \\
(\mathrm{ppm})\end{array}$ & $\begin{array}{l}\text { Gas volume } \\
\text { range }(\mathrm{Cm} 3)\end{array}$ & $\begin{array}{c}\mathrm{H}_{2} \mathrm{~S} \text { adsorption } \\
\text { (gH } 2 \mathrm{~S} / \text { gAdsorbent) } \\
\text { [Ref.] }\end{array}$ \\
\hline 1 & Activated carbon & 121.85 & 3000 & $0.00036-0.021$ & $0.005 / 0.295^{42}$ \\
\hline 2 & $\begin{array}{l}\text { Activated carbon cloth } \\
\text { modified by ammonia } \\
\text { treatment }\end{array}$ & 25 & 5000 & $0.00044-0.052$ & $0.018 / 0.358^{43}$ \\
\hline 3 & $\begin{array}{l}\text { Graphene/Graphite } \\
\text { oxide with copper } \\
\text { hydroxy chlorides }\end{array}$ & 25 & 1000 & $0.0015-0.064$ & $0.007 / 0.159^{44}$ \\
\hline 4 & $\begin{array}{l}\text { Alkaline activated } \\
\text { carbon }\end{array}$ & 25 & 5000 & $0.00044-0.052$ & $0.018 / 0.358^{45}$ \\
\hline 5 & $\begin{array}{c}\text { Alkaline carbon } \\
\text { nanotubes }\end{array}$ & 30 & 10000 & $0.0044-0.13$ & $0.06 / 1.86^{46}$ \\
\hline 6 & RGO- $N$-(piperazine) & 90 & 60000 & $0.002-0.003$ & $2 / 2.2$ \\
\hline 7 & GO & 90 & 60000 & $0.002-0.003$ & $1.9 / 2.2$ \\
\hline 8 & RGO & 90 & 60000 & $0.002-0.003$ & $1.8 / 2.2$ \\
\hline
\end{tabular}


Table 4. Determined isotherm model constants for the adsorption of $\mathrm{H}_{2} \mathrm{~S}$ on RGO-N-(piperazine), GO and RGO.

\begin{tabular}{|c|c|c|c|c|}
\hline \multirow[t]{2}{*}{ Equation/ Isotherm } & \multirow[t]{2}{*}{ Parameter } & \multicolumn{3}{|c|}{ Adsorbents } \\
\hline & & $\begin{array}{l}\text { RGO-N- } \\
\text { (piperazine) }\end{array}$ & GO & RGO \\
\hline \multirow{3}{*}{$\begin{array}{l}\text { Langmuir } \\
y=\frac{a x}{1+k x}\end{array}$} & $\mathrm{a}$ & 5.38 & 4.324 & 2.88 \\
\hline & $\mathrm{k}$ & 4.228 & 3.657 & 1.94 \\
\hline & $\mathrm{R}^{2}$ & 0.9844 & 0.9811 & 0.9784 \\
\hline \multirow{2}{*}{$\begin{array}{l}\text { Toth } \\
a x\end{array}$} & $\mathrm{a}$ & 3.34 & 2.824 & 1.764 \\
\hline & $\mathrm{b}$ & 3.235 & 2.242 & 1.845 \\
\hline \multirow{2}{*}{$y=\overline{\left(1+(b x)^{c}\right)^{\frac{1}{c}}}$} & $\mathrm{c}$ & 2.081 & 3.084 & 7.054 \\
\hline & $\mathrm{R}^{2}$ & 0.994 & 0.988 & 0.991 \\
\hline \multirow{3}{*}{$\begin{array}{l}\text { Freundlich } \\
y=a x^{\frac{1}{n}}\end{array}$} & $\mathrm{a}$ & 1.076 & 1.065 & 1.071 \\
\hline & $\mathrm{n}$ & 2.597 & 2.248 & 1.411 \\
\hline & $\mathrm{R}^{2}$ & 0.9681 & 0.9621 & 0.9601 \\
\hline \multirow{4}{*}{$y=\frac{a}{2 s} \ln \left[\frac{1+b e^{s} x}{1+b e^{-s} x}\right]$} & $\mathrm{a}$ & 1.294 & 1.252 & 1.23 \\
\hline & $\mathrm{b}$ & 4.298 & 2.854 & 1.477 \\
\hline & $\mathrm{s}$ & 0.00917 & 0.00845 & 0.00712 \\
\hline & $\mathrm{R}^{2}$ & 0.9865 & 0.9812 & 0.9785 \\
\hline \multirow{3}{*}{$\begin{array}{l}\text { Sips } \\
y=\frac{a(b x)^{\frac{1}{n}}}{}\end{array}$} & $\mathrm{a}$ & 1.123 & 1.1221 & 1.121 \\
\hline & $\mathrm{b}$ & 5.219 & 3.845 & 2.786 \\
\hline & $\mathrm{n}$ & 0.7887 & 0.7231 & 0.6864 \\
\hline $1+(b x)^{\frac{1}{n}}$ & $\mathrm{R}^{2}$ & 0.997 & 0.9811 & 0.9894 \\
\hline
\end{tabular}




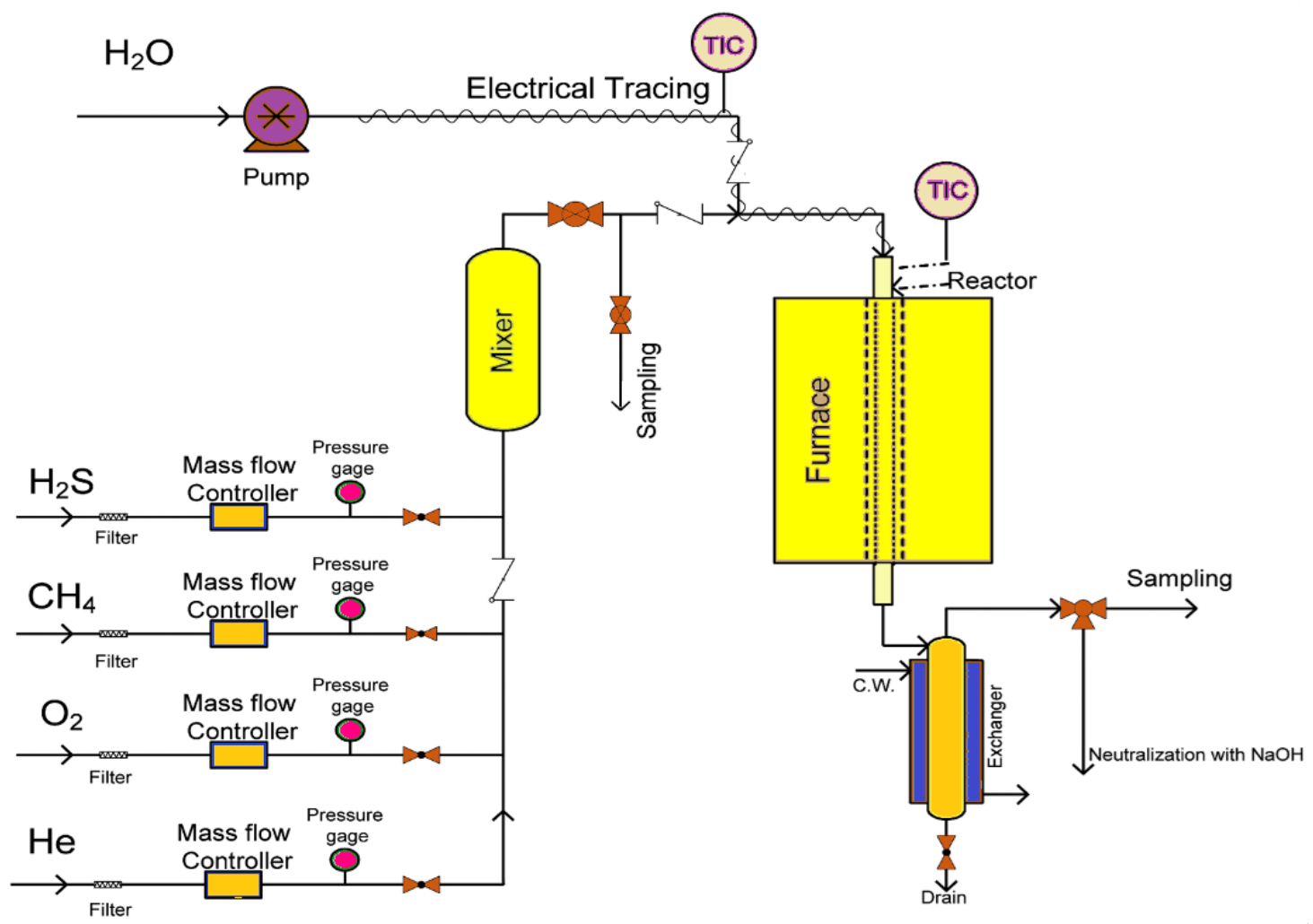

Fig. 1. Schematic view of the setup used for the $\mathrm{H}_{2} \mathrm{~S}$ removal experiments.

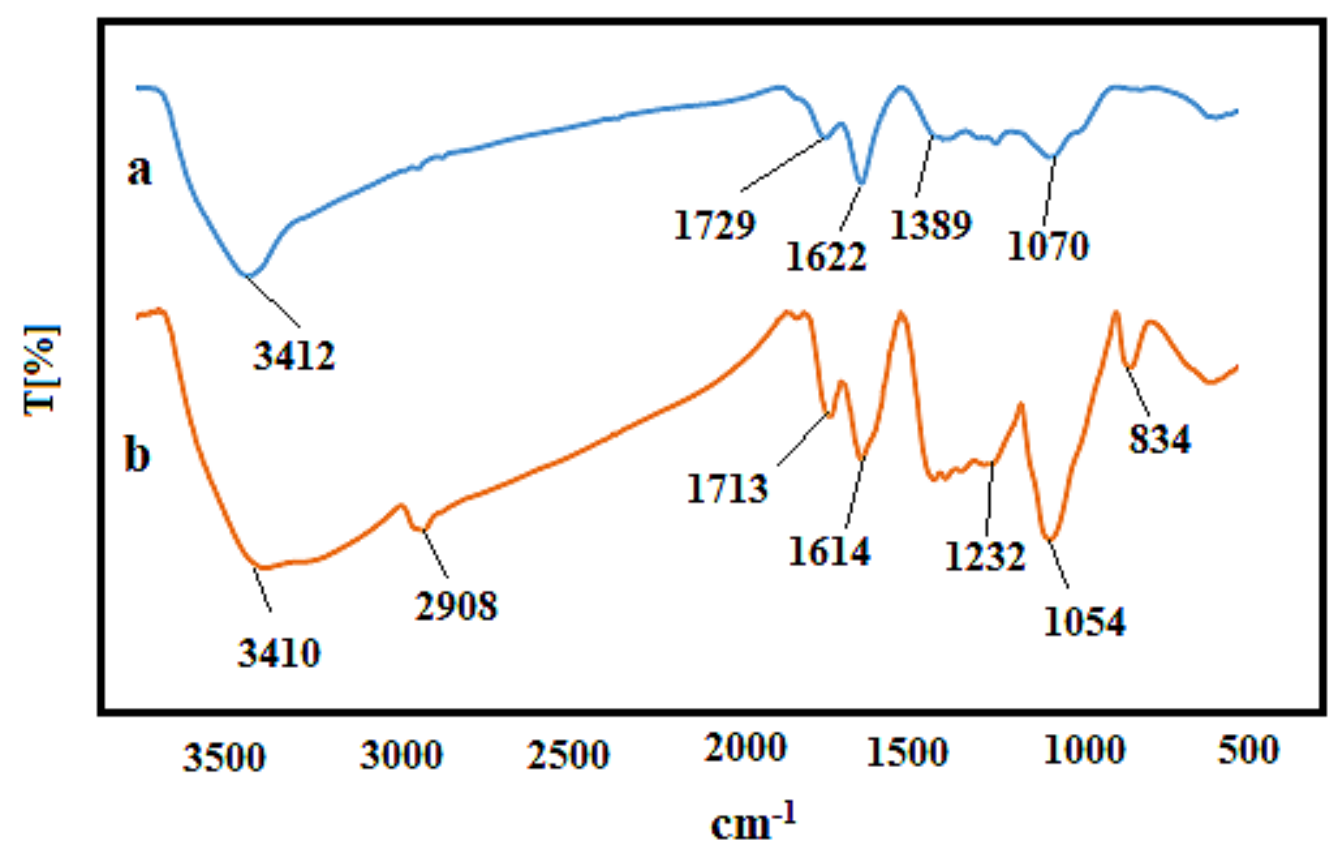

Fig. 2. FT-IR spectra for (a) GO and (b) RGO-N-(piperazine). 


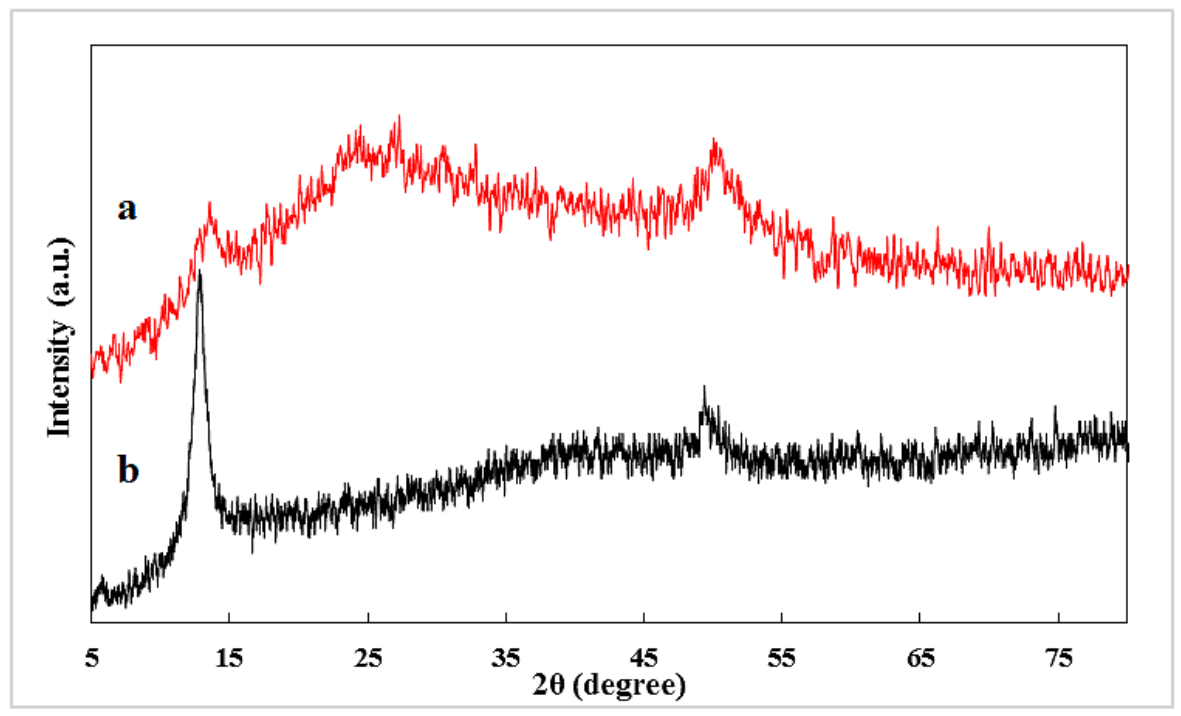

Fig. 3. XRD patterns of (a) GO and (b) RGO-N-(piperazine). 

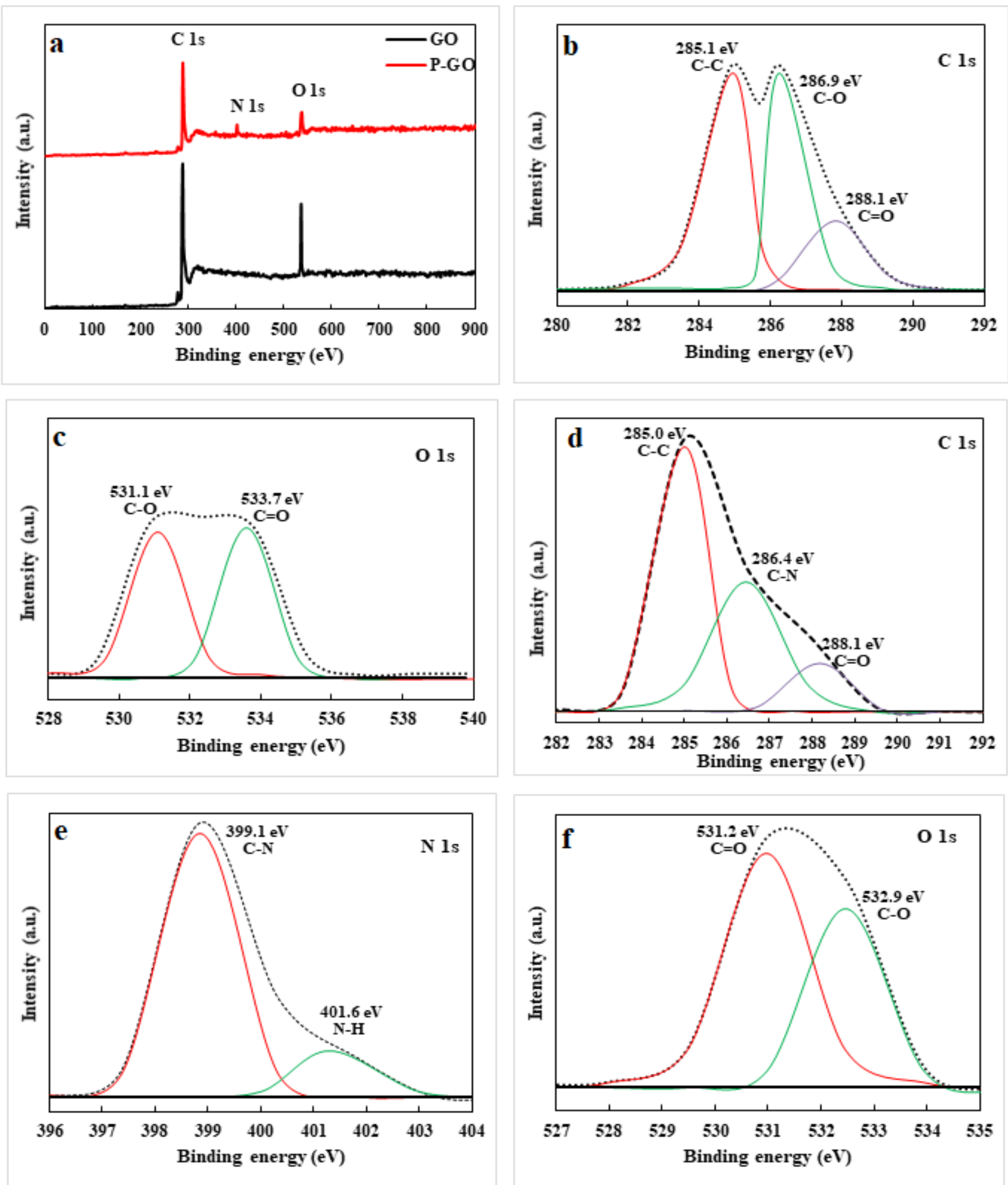

Fig. 4. (a) X-ray photoelectron spectroscopy of GO and RGO-N-(piperazine), (b) C 1s XPS spectra of GO, (c) O 1s XPS spectra of GO, (d) C 1s XPS spectra of RGO-N-(piperazine), (e) N 1s spectra of RGO-N-(piperazine), and (f) O 1s XPS spectra of RGO-N-(piperazine). 

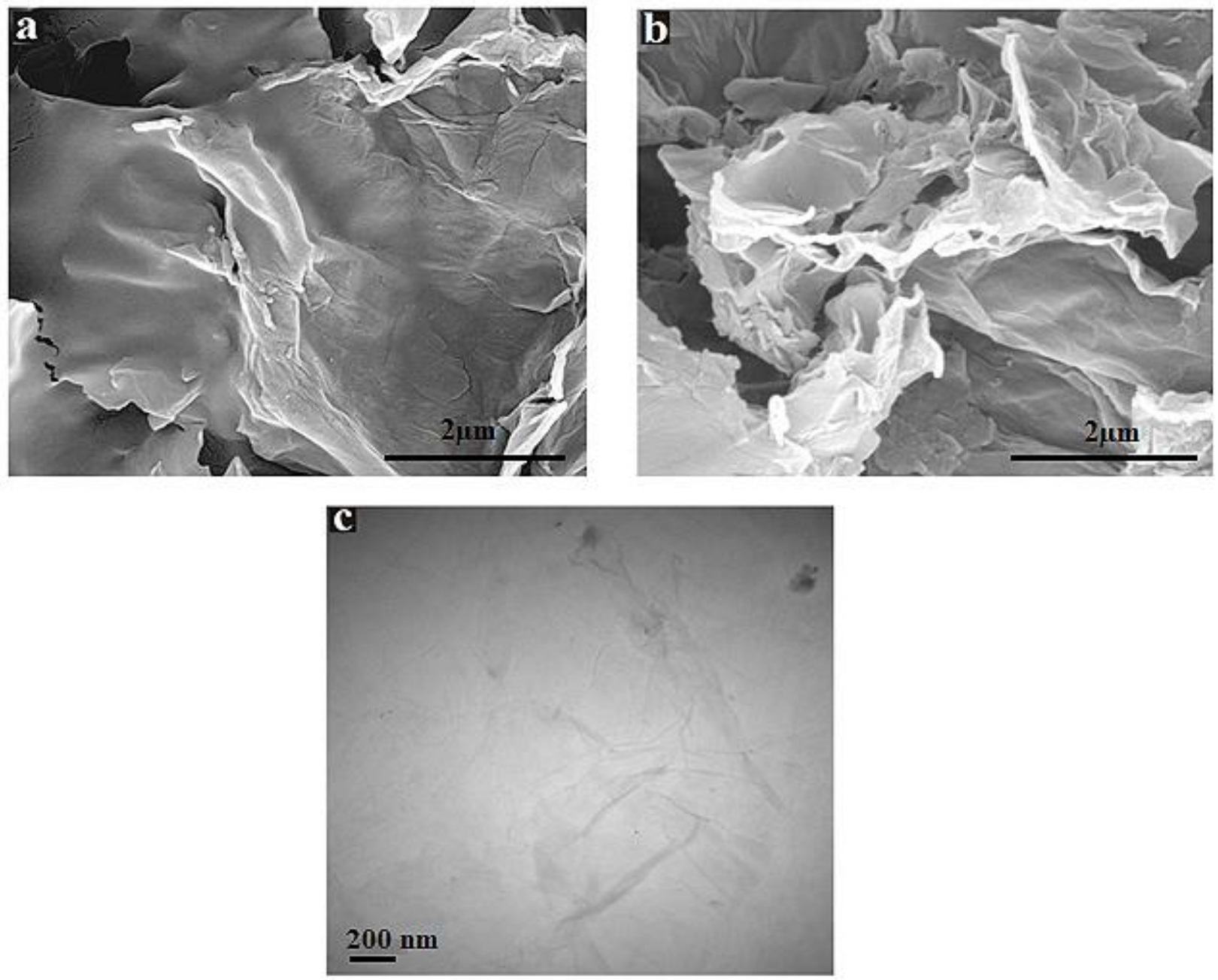

Fig. 5. The SEM images of (a) GO, (b) RGO-N-(piperazine), and (c) TEM images of RGO-N-(piperazine).

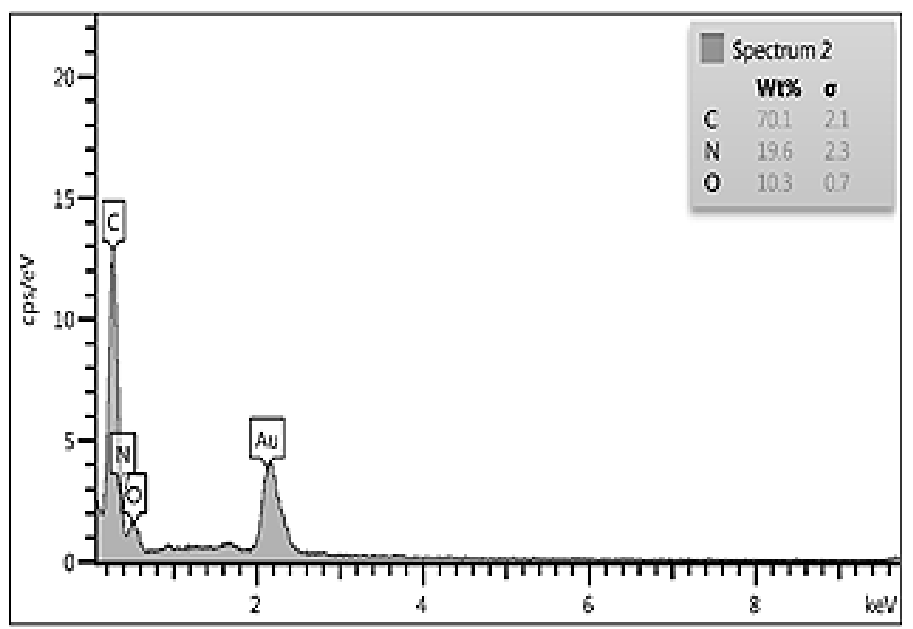

Fig. 6. The EDX of RGO-N-(piperazine). 


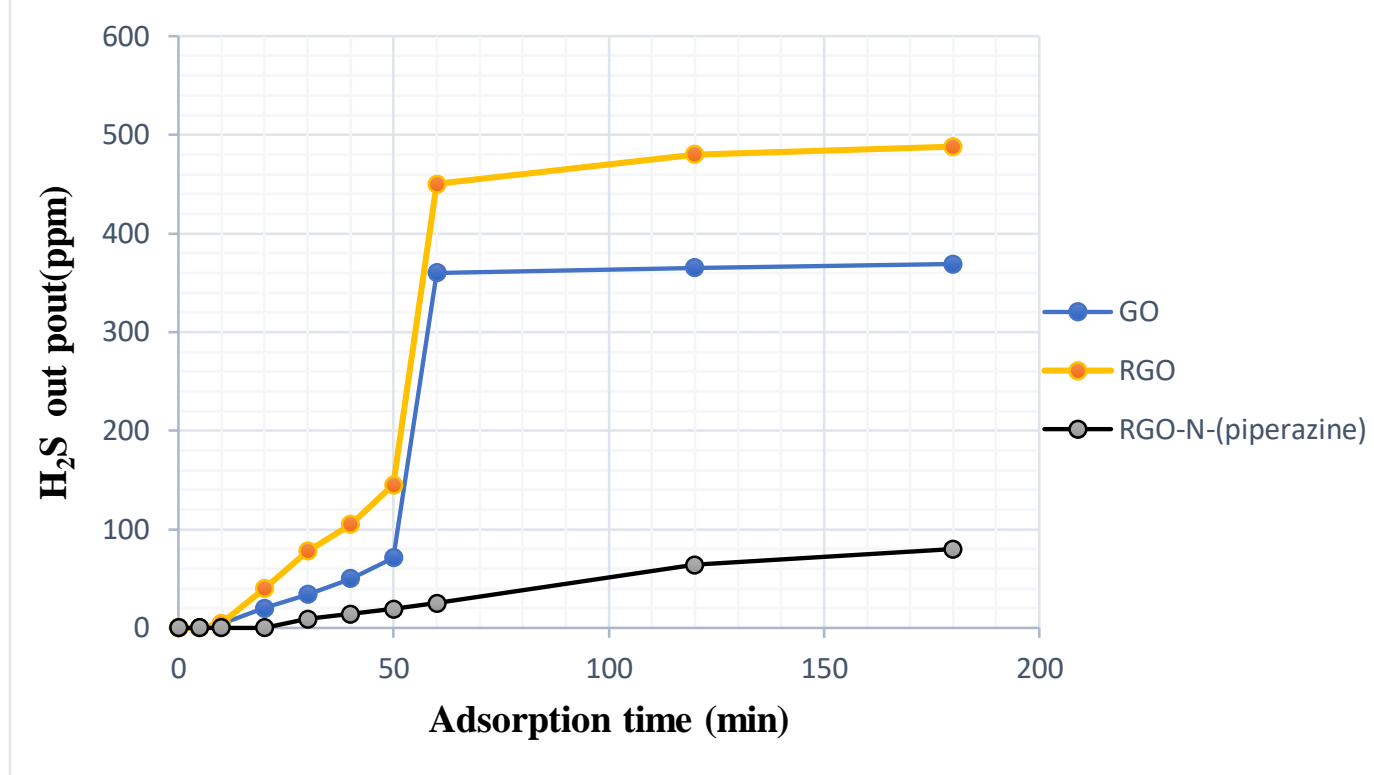

Fig 7. Breakthrough curve of $\mathrm{H}_{2} \mathrm{~S}$ for GO, RGO, RGO-N-(piperazine).

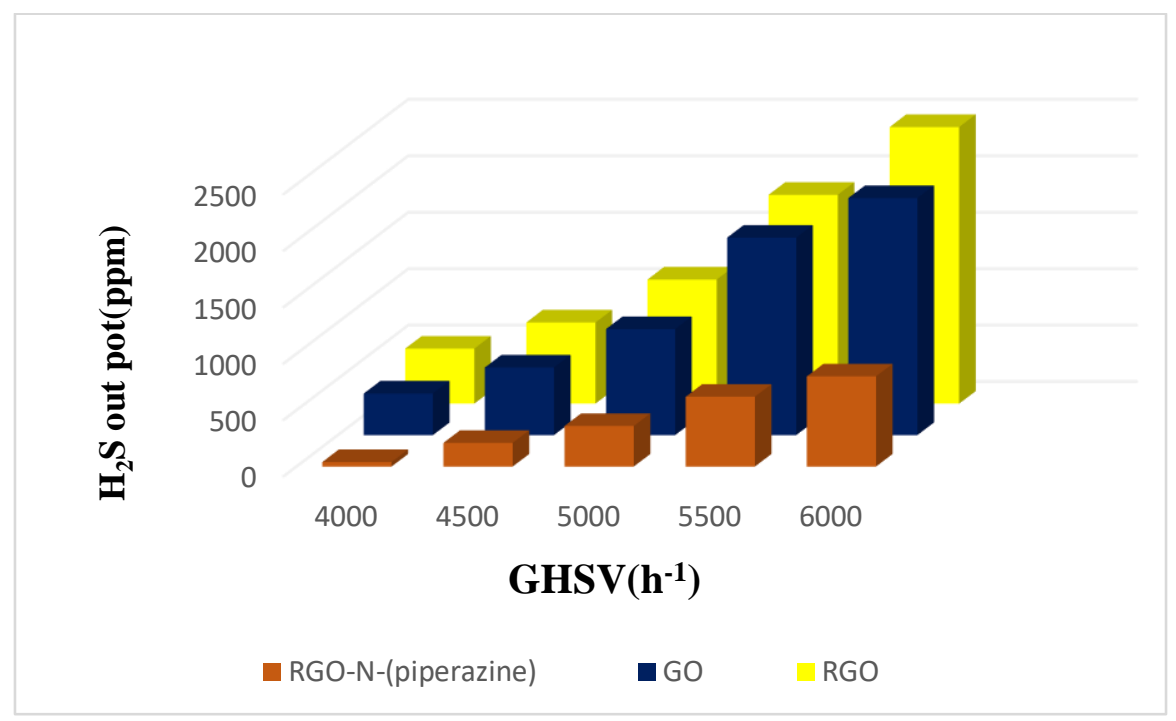

Fig. 8. The effect of GHSV on the H2S adsorption for the nano adsorbents GO, RGO, RGO-N-(piperazine). 


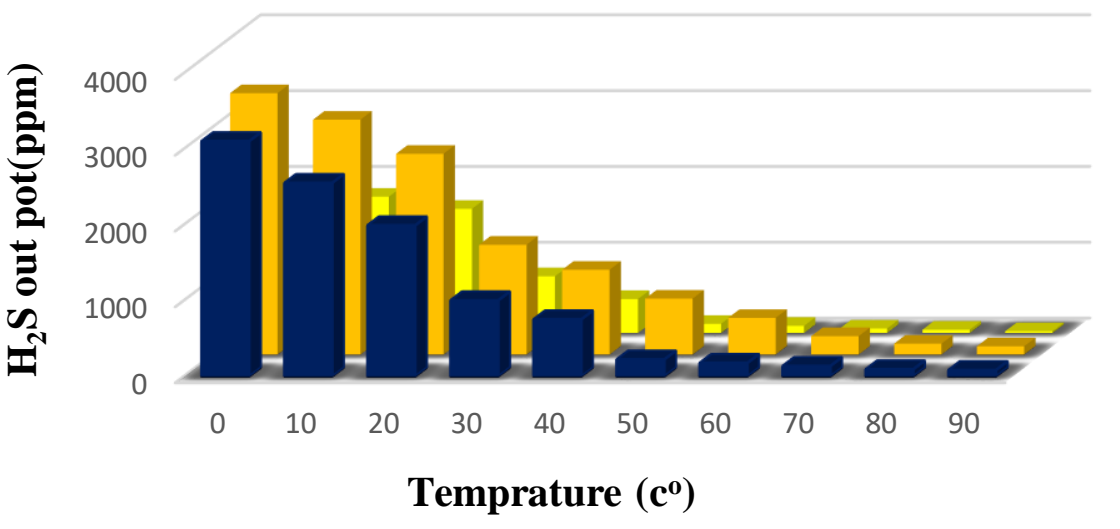

口GO $\square$ RGO $\square$ RGO-N-(piperazine)

Fig. 9. The effect of temperature on the $\mathrm{H}_{2} \mathrm{~S}$ adsorption for the nano adsorbents $\mathrm{GO}, \mathrm{RGO}, \mathrm{RGO}-\mathrm{N}$-(piperazine). 

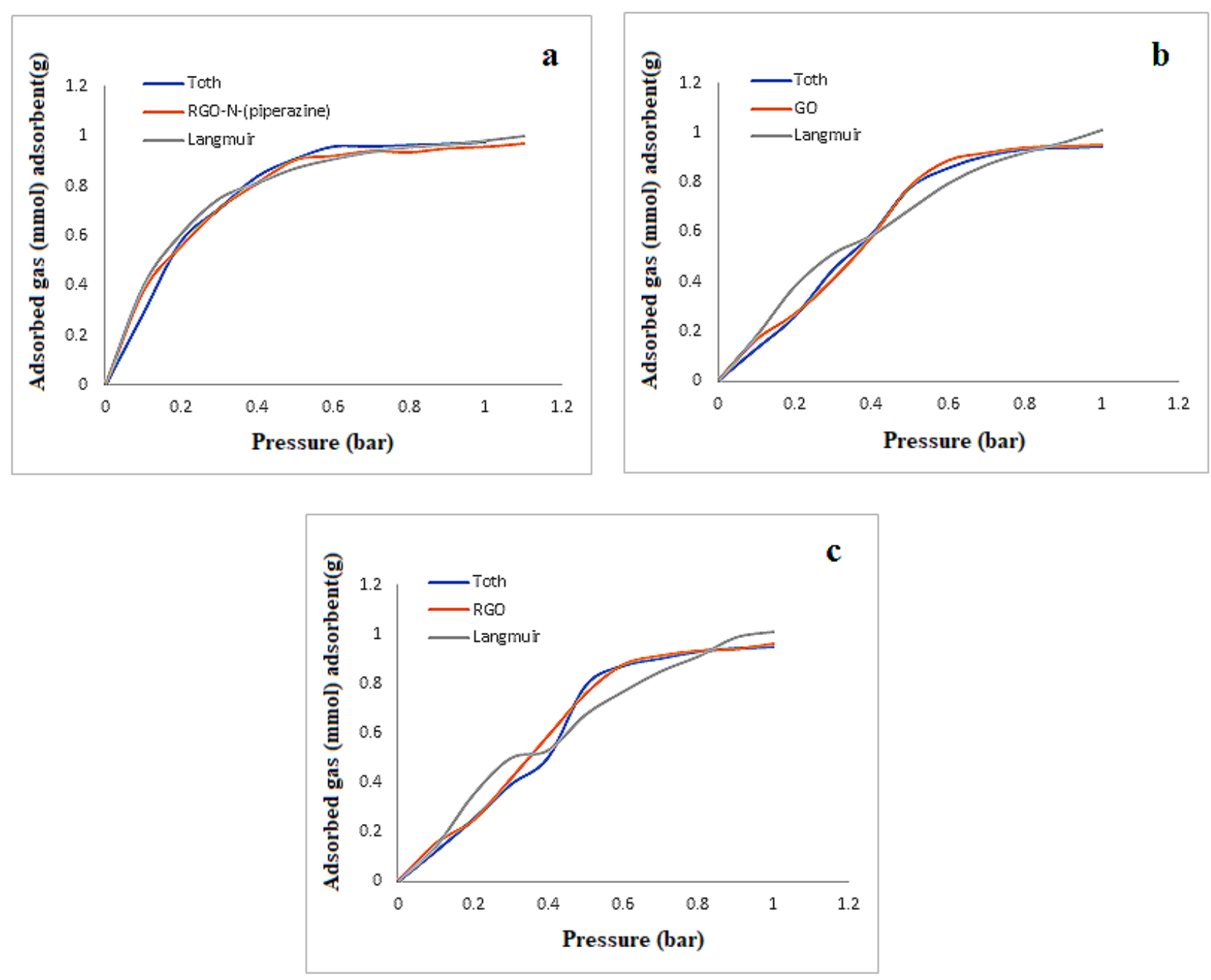

Fig. 10. Fit adsorption data of $\mathrm{H}_{2} \mathrm{~S}$ by (a) RGO-N-(piperazine), (b) GO and (c) RGO using Langmuir and Toth models. 

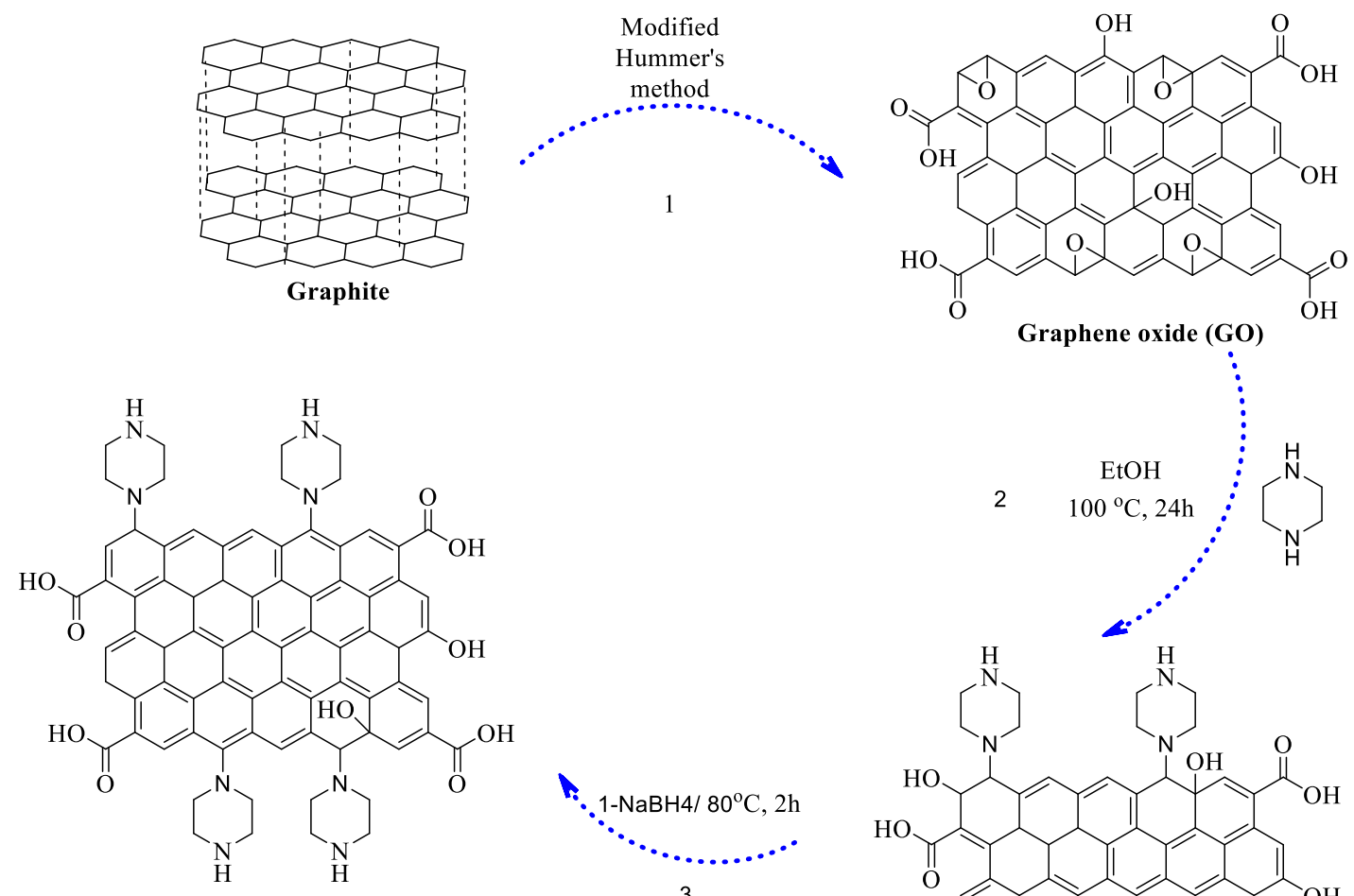

RGO- $N$-(Piperidine)
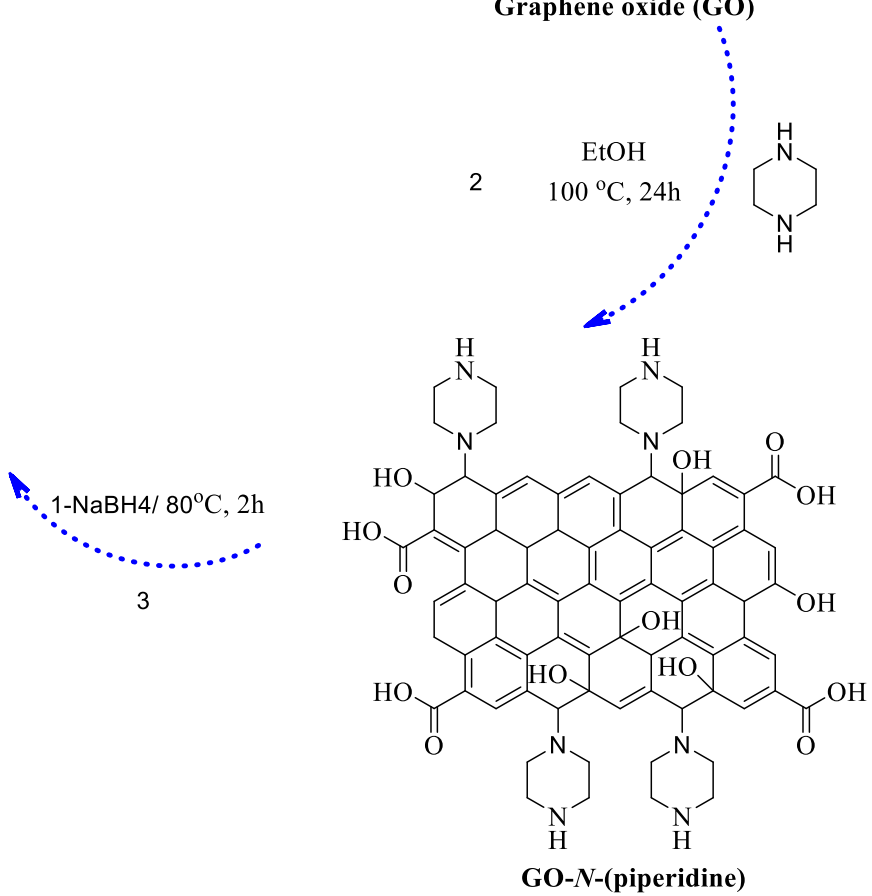

Scheme 1. The Synthetic route to nano piperazine grafted-reduce graphene oxide RGO-N-(piperazine). 